\title{
Estrategias de dinamización turístico cultural: caso de estudio Santiago de Píllaro
}

\section{Cultural tourism dinamization strategies: Case study Santiago de Píllaro}

\author{
Danny Fernando Chiriboga Barba ${ }^{1}$, Héctor Ayala Castro R. ${ }^{2}$, Deicy Magaly Patiño Cabrera ${ }^{3}$, Fabián Camilo Tapia ${ }^{4}$, \\ Tania Cecilia Chiriboga Barba ${ }^{5}$ \\ 凶: mathtuning7@hotmail.com
}

\author{
1 Universidad de las Fuerzas armadas ESPE. Campus Universitario, Departamento de Ciencias Económicas. \\ Av. Gral. Rumiñahui s/n. Sangolquí, Ecuador. \\ 2 Universidad de La Habana-Cuba, Facultad de Turismo. 3 Consultora en Gastronomía y Turismo. Quito, Ecuador. \\ 4 Universidad Central. Quito, Ecuador. 5 IPG Mediabrands, Directora de negociaciones.
}

\begin{abstract}
Resumen
El presente trabajo analiza la importancia de las estrategias de dinamización turístico cultural como un aporte al desarrollo sostenible en el cantón Santiago de Píllaro. El objetivo de este artículo es proponer estrategias de dinamización turístico-cultural como parte del desarrollo económico-social del cantón para la valorización del patrimonio y mejoramiento de las facilidades turísticas en un ambiente de sostenibilidad. Se realizó una investigación descriptiva con un enfoque cuantitativo a través de la aplicación de una encuesta a una muestra significativa de turistas que visitan el cantón, y para el análisis de los resultados se aplicó Chi cuadrado que descartó la hipótesis nula y aceptó la hipótesis de estudio. Los resultados determinaron que a esta ciudad llegan muchos turistas nacionales en la diablada pillareña, sin embargo, el resto del año la afluencia no es significativa repercutiendo en el desarrollo turístico, por lo cual a partir de los resultados obtenidos se llegó a determinar (27) estrategias.
\end{abstract}

Palabras clave: Estrategias, turístico-cultural, valorización, desarrollo, afluencia.

\begin{abstract}
This paper analyses the importance of the strategies of cultural tourism dynamization as a contribution to sustainable development in the canton of Santiago de Píllaro. The objective of this article is to propose strategies of tourism-cultural dynamization as part of the economic-social development of the canton for the valorisation of the patrimony and improvement of the tourist facilities in an environment of sustainability. A descriptive investigation was carried out with a quantitative approach through the application of a survey to a significant sample of tourists visiting the canton, and for the analysis of the results was applied Chi square that ruled out the null hypothesis and I accept the study hypothesis. The results determined that this city has come many national tourists in the Diablada Pillareña however the remainder of the year the influx is not significant affecting the tourism development, so from the results obtained was reached Determine (27) strategies.
\end{abstract}

Keywords: Strategies, tourism-cultural, valorization, development, affluence. 


\section{Introducción}

El cantón Santiago de Píllaro no cuenta con una orientación consciente e integral encaminada a mejorar los atractivos turísticos y facilidades que aporten al desarrollo del turismo cultural y su aprovechamiento, de ahí que se hace necesario dinamizar los recursos culturales por medio de estrategias que fomenten, robustezcan y desarrollen el lugar en beneficio del progreso y posicionamiento en el mercado turístico.

Para comprender la importancia que tienen las estrategias de dinamización para el progreso turístico del cantón, es necesario explicar que estas se caracterizan por cambiar el manejo turístico, mejoran las facilidades, fortalecen la accesibilidad, además tienen particularidades que lo acercan a un plan de desarrollo, al mismo tiempo las estrategias contribuyen en el mejoramiento de diferentes modelos como el de planificación y competitividad turística, se debe agregar que también contribuyen a la gestión del territorio especialmente en los destinos turísticos emergentes.

Como antecedentes Cañas \& Arnandis (2014) explican que en la búsqueda de hacer que el turismo sea más competitivo en España se creó el Plan FUTURES (1992-1995), siendo el primer plan nacional de política turística para mejorar la competitividad y consolidación del turismo como motor estratégico, posterior a este nace el Plan FUTURES II (1996-1999), que se enfocó en los principios de corresponsabilidad, la concentración de actuaciones e integración de las iniciativas empresariales con los de las administraciones.

Es importante señalar que en este segundo plan se crean los Planes de Excelencia y Dinamización Turística dirigida a destinos emergentes con patrimonios culturales o naturales que se encuentran en fase de mejoramiento. Estos planes utilizan estrategias de competitividad, desarrollo y crecimiento. Al respecto Sacatoro (2013) destaca la importancia de diseñar estrategias en la dinamización turística como instrumento de intervención que exige la coordinación entre diferentes administraciones públicas y privadas.

En esta misma línea Montejaque (2015:1) agrega que la planificación de estrategias de dinamización favorece el crecimiento turístico y económico de una zona ya que se aprovecha las características del lugar con la creación de nuevos productos que deben estar cohesionados con el territorio. Además, la Organización Comunidad de Madrid (2016:29) sostiene que las estrategias pueden aportar a la inno- vación de los productos turísticos, mejorar los mecanismo de cooperación interterritorial, y fortalecer la gestión entre distintos organismos y la comunidad.

En esta misma línea Ivars (2002:40) en Almeida et al. (2015:201-226) enfatiza que la dinamización muestra su mejor rostro cuando se crean estrategias que aprovechen los recursos culturales, y fortalezcan la identidad de los habitantes. Al respecto Garzan (2017:10) agrega que hay que evitar la comercialización de las ciudades desde un punto de vista general, a partir de grandes eventos, sino más bien dando la oportunidad a nuevos productos turísticos por medio de estrategias que dinamicen el sector aprovechando la cultura como factor diferenciador.

Con el fin de tener una base referencial sobre la incidencia que han tenido los Planes de Dinamización Turística, en adelante PDT, se ha realizado el estudio de casos de los siguientes territorios que muestran realidades geográficas con procesos de desarrollo diferentes, sin tradición turística, y con escasa competitividad territorial dentro de las lógicas de desarrollo.

En el caso de la Junta de Comunidades Castilla-La Mancha (2016:1) en España, el Reporte de criterios de Baremación proyectos Leader Feader (2001) revela que las estrategias del PDT contribuyeron al desarrollo del turismo rural, ya que se crearon nuevos productos turísticos de calidad ligados al patrimonio y ambiente.

Otro ejemplo a tener en cuenta es el PDT de la ciudad de Almería señalado por Consultur (2002) como la herramienta que permitió reactivar el turismo por medio de una adecuada planificación con base en un diagnóstico del cual se desprendieron estrategias, con resultados económicos y socioculturales destacados, que mejoraron la identidad y autoestima de los pobladores, quienes comprendieron la importancia que tiene el trabajo entre el sector público y privado.

Por otro lado, y con similares resultados, los PDT aplicados en las ciudades de Sudamérica han solucionado el decrecimiento turístico, como es el caso de la Comunidad Zapote de Picachos en México, cuyo PDT contiene estrategias encaminadas a recuperar y valorizar el patrimonio cultural, ecológico e histórico del pueblo Huichol.

En esta misma línea el Instituto de desarrollo turístico de México (2014:1-4) muestra el PDT de la ciudad de Atlixco, que fue creado con el fin de apro- 
vechar los atractivos culturales mediante la utilización de varias estrategias agrupadas en cinco acciones dirigidas al entorno empresarial, la experiencia, el destino, la innovación y la confianza.

De igual manera el Gobierno Municipal de la Paz (2016:1-6) ha creado un PDT para la laguna de Pampalarama contribuyendo de esta forma con las aspiraciones de desarrollo económico de sus habitantes. En cuanto a su proceso metodológico se hizo un diagnóstico, se identificaron sus recursos turísticos, y finalmente se planteó estrategias de dinamización.

En Costa Rica la iniciativa de crear un PDT, nace según Cañada (2017:17) por el anhelo de fortalecer la identidad agroalimentaria y generar oportunidades de desarrollo para los pobladores, por eso sus estrategias están encaminadas al sector público y privado.

En el caso de Ecuador, los PDT comienzan a llamar la atención, especialmente de los centros de educación Superior e investigadores en el ámbito turístico, como es el caso de Reyes (2016); Valladares (2016:95) y Sacatoro (2013), quienes concuerdan en la importancia que tienen las estrategias en un PDT, ya que estas fortalecen el entorno turístico, mejoran las facilidades, y crean identidad, además sugieren su aplicación.

Estas premisas y la riqueza cultural del sector han sido importantes en la decisión de plantear estrategias para el cantón Santiago de Píllaro, ya que se cree firmemente que aportarían eficientemente como el hilo conductor que incentive el desarrollo, corrigiendo problemas como la limitada afluencia de turistas nacionales y la casi nula visita de turistas internacionales. Además, sus facilidades turísticas tienen limitantes que han impedido su desarrollo como es el caso del hospedaje, que de acuerdo con el GAD Municipal Píllaro (2015: 157) se limitan a siete lugares que no abastecen cuando hay afluencia turística, ocasionando que muchos opten por buscar otros lugares para hospedarse como Ambato, Baños o Latacunga, con respecto a los restaurantes hay variedad, pero no ofrecen una atención con esmerada calidad y excelencia.

Las facilidades turísticas en general no son las adecuadas para la atención a los turistas por lo que el turismo tiene un freno que se ve reflejado en la pérdida de interés por crear negocios relacionadas con esta actividad, por lo tanto, no se ha logrado establecer acciones que integren los atractivos turísticos culturales del cantón.
En consonancia con lo expresado, el objetivo de la investigación es proponer estrategias de dinamización turístico-cultural como parte del desarrollo económico-social del cantón para la valorización del patrimonio y mejoramiento de las facilidades turísticas en un ambiente de sostenibilidad.

En cuanto a la hipótesis, se buscó conocer si las estrategias de dinamización turístico-cultural contribuyen positivamente en al desarrollo del cantón Santiago de Píllaro y mejoramiento de sus facilidades turísticas.

\section{Materiales y métodos}

\section{1. Área de estudio}

El cantón Santiago de Píllaro está situado en las faldas de la Cordillera Central de los Andes, al noreste de la provincia de Tungurahua; a $1^{\circ} 10^{\prime}$ de latitud sur y a $78^{\circ} 32^{\prime}$ de longitud occidental, limita al norte con la provincia de Cotopaxi (cantón Salcedo) y la provincia de Napo; al sur Patate, al este la provincia de Napo (cantón Tena) y al oeste la provincia de Cotopaxi (cantón Salcedo, cantón Ambato y cantón Pelileo), su altitud va desde los 2.210 a los $4.300 \mathrm{msnm}$, con una superficie de 44543.06 ha. Además, está formado por ocho parroquias que son: Baquerizo Moreno, Emilio María Terán, Marcos Espinel, Píllaro, Presidente Urbina, San Andrés, San José de Poaló, San Miguelito.

Su población total, según el Instituto Nacional de Estadística y Censos (2010), es de 38.357 habitantes de los cuales 20.266 son mujeres y 18.091 son hombres, es decir que por cada 100 mujeres existen 94 hombres. Además, INEC (2010: 2) manifiesta que el cantón Santiago de Píllaro concentra su mayor parte de población en el área rural, y la mayoría es casada.

En lo que se refiere a su historia según los cronistas de la época española Píllaro es un lugar que fue habitado por grupos humanos con características similares a los Caras, Yatchil, Quitus, y Cayapas. De este último grupo provendría la terminología Píllaro que significa Pilla-Relámpago y Ru-hueco o altar por lo tanto Píllaro significa altar del trueno. El español Don Antonio Clavijo en 1.570, funda el pueblo de Píllaro por comisión especial de la Audiencia de Quito y en el Período Republicano, el 25 de julio de 1.851, por Decreto Supremo firmado en Latacunga, se crea oficialmente el cantón Píllaro, siendo Jefe Supremo el general José María Urbina, posteriormente incor- 
poraría el nombre del apóstol Santiago y patrono de las armas españolas por lo que hoy se le conoce como Santiago de Píllaro.

\subsection{Metodología}

La investigación tiene un enfoque cuantitativo de tipo descriptivo analítico-exploratorio con análisis documental, se revisaron artículos, investigaciones y documentos para entender el tema de investigación. La población de estudio se estableció por el número de turistas nacionales que se hospedan en los hoteles del cantón Santiago de Píllaro, en enero 2017, mes de mayor afluencia turística por la diablada pillareña, en este sentido el cálculo del tamaño de la muestra es el siguiente

$$
\frac{Z^{2} P \cdot Q \cdot N}{Z^{2} P \cdot Q+N e^{2}}
$$

\section{Donde:}

$n$ : tamaño de la muestra

$z$ : nivel de confiabilidad (1.96)

$P$ : probabilidad de no ocurrencia $(0.5)$

$Q$ : probabilidad de ocurrencia $(0.5)$

$e$ : error de muestreo $(0.05)$

Reemplazando los datos:

$$
\mathrm{x}=\frac{(1.96)^{2}(0.5) \cdot(0.5) \cdot(2256)}{(1.96)^{2} \cdot(0.5) \cdot(0.5)+(564)(0.05)^{2}}
$$

$n=328$ Muestras

A la muestra seleccionada se le aplicó una encuesta in situ, y se tabularon los resultados de la encuesta con la herramienta SPSS. Para el análisis de datos se emplearon tablas para su mejor comprensión.
Además, para comprobar la hipótesis se utilizó la variable once, estrategias de dinamización, y la variable trece, facilidades turísticas, y se procedió a su tabulación (Tabla 1).

Tabla 1. Método estadístico

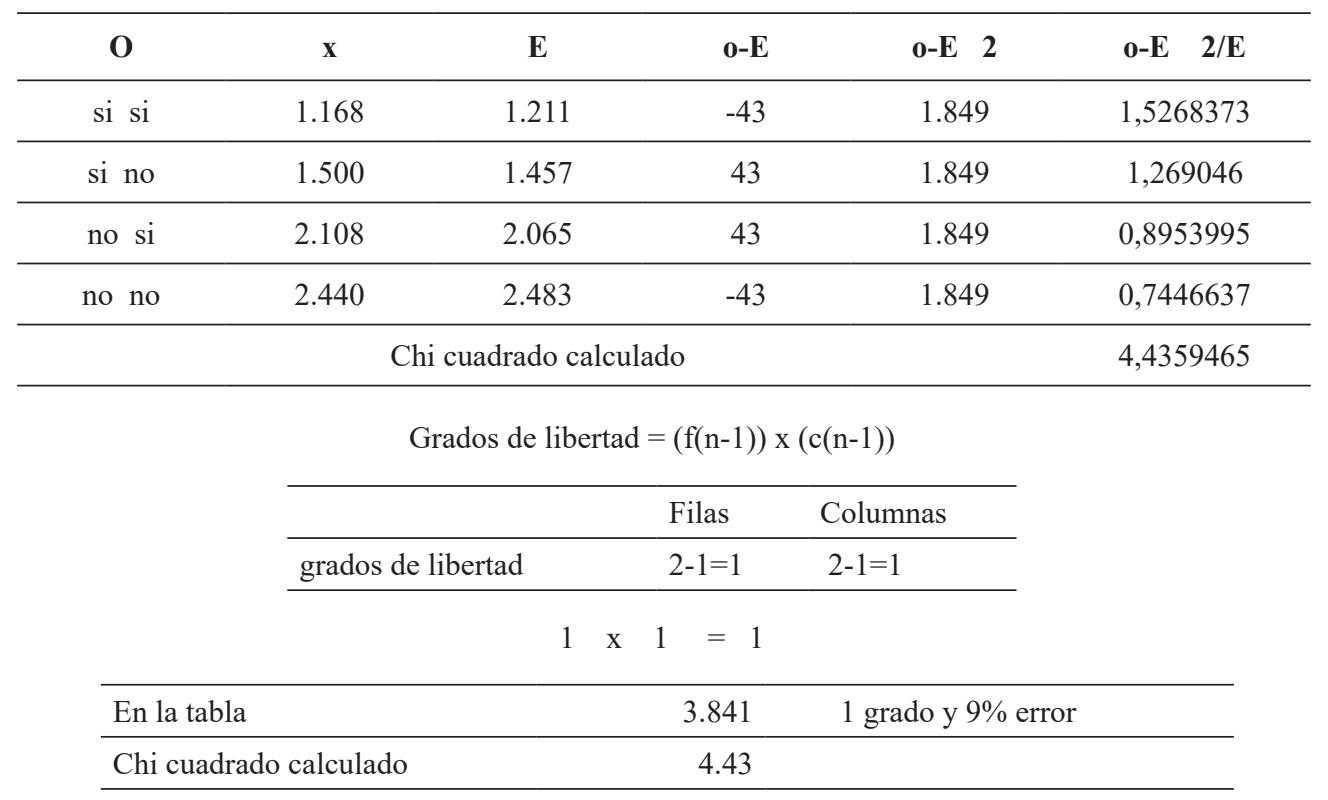


De este cálculo se obtuvo un valor de 4.43 en el método estadístico, que permitió descartar la hipótesis nula y se acepta la hipótesis de estudio. Por tal motivo se ha demostrado probabilísticamente que "Las estrategias de dinamización turístico-cultural contribuyen positivamente en las facilidades turísticas del cantón Santiago de Píllaro". Se utilizó en la tabulación de los resultados la herramienta Excel.

\section{Resultados}

\subsection{Resultados de la encuesta}

Con los resultados procedentes de la encuesta se hizo el análisis por variables procesadas mostrado en la Tabla 2. El perfil del turista se presenta en la Tabla 2, donde se puede verificar que la banda de edad más nutrida es la comprendida entre 26 y 35 años con casi el 44,6\% del total, En cuanto a la proporción de hombres y mujeres existe una relación equilibrada siendo el $52,1 \%$ de los encuestados hombres y el 47,9\% mujeres. En cuanto a la procedencia la mayoría es de la provincia de Pichincha con un 64,6\% seguido de Tungurahua con el 17,7\% $\mathrm{y}$ existe una paridad entre las personas que visitan por primera vez el cantón con un $39,2 \%$ y los que la están visitando por más de dos veces.

Tabla 2. Perfil del turista

\begin{tabular}{|c|c|}
\hline Características & Nacionales \\
\hline Edad & $\begin{array}{l}13,4 \% \text { Entre } 18 \text { y } 25 \\
44,6 \% \text { Entre } 26 \text { y } 35 \text { años } \\
27,1 \% \text { Entre } 36 \text { y } 45 \text { años } \\
6,4 \% \text { Entre } 46 \text { y } 64 \text { años } \\
5,5 \% \text { Más de } 65 \text { años }\end{array}$ \\
\hline Sexo & $\begin{array}{l}47,9 \% \text { Femenino } \\
52,1 \% \text { Masculino }\end{array}$ \\
\hline Lugar de procedencia & $\begin{array}{l}64,6 \% \text { Pichincha } \\
7 \% \text { Cotopaxi } \\
17,7 \% \text { Tungurahua } \\
3,7 \% \text { Imbabura } \\
1,5 \% \text { El Oro } \\
1,5 \% \text { Guayas } \\
0,3 \% \text { Azuay } \\
3 \% \text { Loja } \\
0,6 \% \text { Napo }\end{array}$ \\
\hline Cuantas veces ha visitado Píllaro & $\begin{array}{l}39,2 \% \text { Primera vez } \\
21,1 \% \text { Segunda vez } \\
\text { 39,7 \% Más de dos veces }\end{array}$ \\
\hline Estado civil & $\begin{array}{l}49,1 \% \text { Soltero/a } \\
22,6 \% \text { Casado/a } \\
10,7 \% \text { Divorciado/a } \\
14,6 \% \text { Unión libre } \\
3 \% \text { Viudo/a }\end{array}$ \\
\hline Nivel de instrucción & $\begin{array}{l}0 \% \text { Primaria } \\
78 \% \text { Secundaria } \\
14,6 \% \text { Superior } \\
7,3 \% \text { Tecnología } \\
0 \% \text { Post-Grado }\end{array}$ \\
\hline Ocupación & $\begin{array}{l}\text { 49,4\% Estudiante } \\
3 \% \text { Empleado público } \\
31,1 \% \text { Empleado privado } \\
\text { 4,6\% Desempleado } \\
2,7 \% \text { Jubilado } \\
9,1 \% \text { Independiente }\end{array}$ \\
\hline
\end{tabular}




\begin{tabular}{ll}
\hline & $42,1 \%$ Amigos \\
& $48,8 \%$ Familia \\
& $8,2 \%$ Pareja \\
& $0,9 \%$ Compañeros del trabajo \\
& $0 \% \quad$ Solo
\end{tabular}

Respecto al estado civil el $49,1 \%$ es soltero. El nivel de estudios predominante es el secundario con el $45 \%$, seguido de estudios superiores $14,6 \%$ y de tecnología 7,3\%. El 33,1\% es empleado privado junto al $12,5 \%$ que es independiente además el $44,4 \%$ viaja con sus familias seguido del $38.3 \%$ que lo hace con sus amigos. Por último, el gasto que hace es de $\$ 15$ diarios que representa el 69,2\% y se movilizan mayoritariamente en transporte pú- blico. Además, es importante mencionar que no se ha registrado a turistas extranjeros.

Como se presenta en la Tabla 3, el mayor medio de la comunicación intencional o dirigida por los gestores del destino pertenece a la información proporcionada por redes sociales como Facebook, y twitter $70.4 \%$, seguido de la página web $14 \%$. Por su parte, el medio de comunicación no intencional o informal representa el $15.5 \%$. El resto de ítems no fueron señalados.

Tabla 3. Medios de obtención de información del cantón Píllaro.

\begin{tabular}{|c|c|c|c|c|c|}
\hline \multicolumn{6}{|c|}{ Página Web } \\
\hline & & Frecuencia & Porcentaje & $\begin{array}{l}\text { Porcentaje } \\
\text { válido }\end{array}$ & $\begin{array}{l}\text { Porcentaje } \\
\text { acumulado }\end{array}$ \\
\hline \multirow{3}{*}{ Válido } & SI & 46 & 14,0 & 14,0 & 14,0 \\
\hline & NO & 282 & 86,0 & 86,0 & 100,0 \\
\hline & Total & 328 & 100,0 & 100,0 & \\
\hline \multicolumn{6}{|c|}{ Redes sociales (Facebook, Twitter) } \\
\hline & & Frecuencia & Porcentaje & $\begin{array}{l}\text { Porcentaje } \\
\text { válido }\end{array}$ & $\begin{array}{l}\text { Porcentaje } \\
\text { acumulado }\end{array}$ \\
\hline \multirow{3}{*}{ Válido } & SI & 231 & 70,4 & 70,4 & 70,4 \\
\hline & NO & 97 & 29,6 & 29,6 & 100,0 \\
\hline & Total & 328 & 100,0 & 100,0 & \\
\hline \multicolumn{6}{|c|}{ Televisión, radio } \\
\hline & & Frecuencia & Porcentaje & $\begin{array}{l}\text { Porcentaje } \\
\text { válido }\end{array}$ & $\begin{array}{l}\text { Porcentaje } \\
\text { acumulado }\end{array}$ \\
\hline Válido & NO & 328 & 100,0 & 100,0 & 100,0 \\
\hline \multicolumn{6}{|c|}{ Prensa escrita (Comercio, revistas) } \\
\hline & & Frecuencia & Porcentaje & $\begin{array}{c}\text { Porcentaje } \\
\text { válido }\end{array}$ & $\begin{array}{l}\text { Porcentaje } \\
\text { acumulado }\end{array}$ \\
\hline Válido & NO & 328 & 100,0 & 100,0 & 100,0 \\
\hline
\end{tabular}




\begin{tabular}{lccccc}
\hline \multicolumn{7}{c}{ Boletines, trípticos } \\
\hline Válido & No & 328 & 100,0 & 100,0 & 100,0 \\
\hline \multirow{2}{*}{ Frecuencia } & Porcentaje & $\begin{array}{c}\text { Porcentaje } \\
\text { válido }\end{array}$ & $\begin{array}{c}\text { Porcentaje } \\
\text { acumulado }\end{array}$ \\
\hline \multirow{3}{*}{ Válido } & & Familiares, amigos & & \\
\cline { 2 - 6 } & No & 51 & Porcentaje & $\begin{array}{c}\text { Porcentaje } \\
\text { válido }\end{array}$ & $\begin{array}{c}\text { Porcentaje } \\
\text { acumulado }\end{array}$ \\
\cline { 2 - 6 } & No & 277 & 15,5 & 15,5 & 15,5 \\
\hline
\end{tabular}

La Tabla 4 ha sido elaborada con la finalidad de indagar cuatro áreas estratégicas de dinamización turística que se han considerado para esta investigación siendo la opinión de los turistas de gran importancia ya que su sentir contribuye a definir si hay alguna evidencia de que ya se estén poniendo en práctica.

Hecha esta explicación, y en base a los resultados obtenidos, las áreas estratégicas muestran que no hay claridad en su percepción ni la afirmación de su existencia es contundente, de ahí que el Storytelling como estrategia de marketing de contenidos tiene $47 \%$, seguido de la competitividad $37,2 \%$, desarrollo $34,8 \%$ y crecimiento $30,5 \%$, lo que puede visibilizarse como una ocasión para plantear estrategias que estén dirigidas a dinamizar el cantón.

Tabla 4. Estrategias aplicadas en el cantón Santiago de Píllaro en el ámbito turístico cultural.

\begin{tabular}{|c|c|c|c|c|c|}
\hline \multicolumn{6}{|c|}{ Ser más competitivo } \\
\hline & & Frecuencia & Porcentaje & $\begin{array}{c}\text { Porcentaje } \\
\text { válido }\end{array}$ & $\begin{array}{l}\text { Porcentaje } \\
\text { acumulado }\end{array}$ \\
\hline \multirow{3}{*}{ Válido } & SI & 122 & 37,2 & 37,2 & 37,2 \\
\hline & NO & 206 & 62,8 & 62,8 & 100,0 \\
\hline & Total & 328 & 100,0 & 100,0 & \\
\hline \multicolumn{6}{|c|}{ Tener un mejor desarrollado turístico } \\
\hline & & Frecuencia & Porcentaje & $\begin{array}{l}\text { Porcentaje } \\
\text { válido }\end{array}$ & $\begin{array}{l}\text { Porcentaje } \\
\text { acumulado }\end{array}$ \\
\hline \multirow{3}{*}{ Válido } & SI & 114 & 34,8 & 34,8 & 34,8 \\
\hline & NO & 214 & 65,2 & 65,2 & 100,0 \\
\hline & Total & 328 & 100,0 & 100,0 & \\
\hline \multicolumn{6}{|c|}{ Tener un crecimiento turístico ordenado } \\
\hline & & Frecuencia & Porcentaje & $\begin{array}{l}\text { Porcentaje } \\
\text { válido }\end{array}$ & $\begin{array}{l}\text { Porcentaje } \\
\text { acumulado }\end{array}$ \\
\hline \multirow{3}{*}{ Válido } & SI & 100 & 30,5 & 30,5 & 30,5 \\
\hline & NO & 228 & 69,5 & 69,5 & 100,0 \\
\hline & Total & 328 & 100,0 & 100,0 & \\
\hline \multicolumn{6}{|c|}{ Ofrecer mejores experiencias e historias (Storytelling) } \\
\hline & & Frecuencia & Porcentaje & $\begin{array}{l}\text { Porcentaje } \\
\text { válido }\end{array}$ & $\begin{array}{l}\text { Porcentaje } \\
\text { acumulado }\end{array}$ \\
\hline \multirow{3}{*}{ Válido } & SI & 154 & 47,0 & 47,0 & 47,0 \\
\hline & NO & 174 & 53,0 & 53,0 & 100,0 \\
\hline & Total & 328 & 100,0 & 100,0 & \\
\hline
\end{tabular}


Con respecto a la Tabla 5, los resultados indican que entre los principales motivos de visita se encuentra la identidad local $66,8 \%$, seguido de la búsqueda de conocimientos locales tradicionales $64 \%$, patrimonio cultural $53 \%$, y por último eventos o ferias realizados con el $11,3 \%$ estos resultados muestran que el turista busca interactuar con un entorno socio cultural diferente.

Tabla 5. Motivos de visita al cantón Santiago de Píllaro

\begin{tabular}{ccc|c|c|c} 
& \multicolumn{7}{c}{ Identidad local } \\
& & & & \\
Frecuencia & Porcentaje & $\begin{array}{c}\text { Porcentaje } \\
\text { válido }\end{array}$ & $\begin{array}{c}\text { Porcentaje } \\
\text { acumulado }\end{array}$ \\
\hline \multirow{2}{*}{ Válido } & SI & 219 & 66,8 & 66,8 & 66,8 \\
\cline { 2 - 6 } & No & 109 & 33,2 & 33,2 & 100,0 \\
\cline { 2 - 6 } & Total & 328 & 100,0 & 100,0 & \\
& & & &
\end{tabular}

\begin{tabular}{ccc|c|c|c}
\multicolumn{7}{c}{ Conocimientos especializados tradicionales } \\
\hline & \multicolumn{2}{c}{ Frecuencia } & Porcentaje & $\begin{array}{c}\text { Porcentaje } \\
\text { válido }\end{array}$ & $\begin{array}{c}\text { Porcentaje } \\
\text { acumulado }\end{array}$ \\
\hline Válido & SI & 210 & 64,0 & 64,0 & 64,0 \\
\cline { 2 - 6 } & NO & 118 & 36,0 & 36,0 & 100,0 \\
\cline { 2 - 6 } & Total & 328 & 100,0 & 100,0 & \\
\hline
\end{tabular}

\begin{tabular}{ccc|c|c|c} 
& \multicolumn{7}{c}{ Patrimonio cultural } \\
& & Frecuencia & Porcentaje & $\begin{array}{c}\text { Porcentaje } \\
\text { válido }\end{array}$ & $\begin{array}{c}\text { Porcentaje } \\
\text { acumulado }\end{array}$ \\
\hline Válido & SI & 174 & 53,0 & 53,0 & 53,0 \\
\cline { 2 - 6 } & NO & 154 & 47,0 & 47,0 & 100,0 \\
\cline { 2 - 6 } & Total & 328 & 100,0 & 100,0 & \\
\hline
\end{tabular}

Eventos o ferias realizados

\begin{tabular}{|c|c|c|c|c|c|}
\hline & & Frecuencia & Porcentaje & $\begin{array}{l}\text { Porcentaje } \\
\text { válido }\end{array}$ & $\begin{array}{l}\text { Porcentaje } \\
\text { acumulado }\end{array}$ \\
\hline \multirow{3}{*}{ Válido } & SI & 37 & 11,3 & 11,3 & 11,3 \\
\hline & NO & 291 & 88,7 & 88,7 & 100,0 \\
\hline & Total & 328 & 100,0 & 100,0 & \\
\hline
\end{tabular}

Las facilidades turísticas son tan importantes como los recursos turísticos, ya que las dos se complementan, razón por la cual las respuestas contenidas en la Tabla 6 evidencian claramente que existen problemas que han sido percibidos por todos los encuestados ya que desconocen de la variedad gastronómica el $87 \%$, excursiones locales y rutas $77,1 \%$, centros de información $73,2 \%$, incluso el transporte es una deficiencia que tiene el $71,6 \%$, y el alojamiento $67,4 \%$, por último se encuentran las amenidades con el $63 \%$ y las agencias de viajes $53 \%$. 
Tabla 6. Facilidades turísticas encontradas en la visita al cantón Santiago de Píllaro

\begin{tabular}{|c|c|c|c|c|c|}
\hline \multicolumn{6}{|c|}{ Centros de información } \\
\hline & & Frecuencia & Porcentaje & $\begin{array}{c}\text { Porcentaje } \\
\text { válido }\end{array}$ & $\begin{array}{l}\text { Porcentaje } \\
\text { acumulado }\end{array}$ \\
\hline \multirow{5}{*}{ Válido } & SI & 88 & 26,8 & 26,8 & 26,8 \\
\hline & NO & 240 & 73,2 & 73,2 & 100,0 \\
\hline & Total & 328 & 100,0 & 100,0 & \\
\hline & \multicolumn{5}{|c|}{ Transporte } \\
\hline & & Frecuencia & Porcentaje & $\begin{array}{c}\text { Porcentaje } \\
\text { válido }\end{array}$ & $\begin{array}{l}\text { Porcentaje } \\
\text { acumulado }\end{array}$ \\
\hline \multirow{3}{*}{ Válido } & SI & 93 & 28,4 & 28,4 & 28,4 \\
\hline & NO & 235 & 71,6 & 71,6 & 100,0 \\
\hline & Total & 328 & 100,0 & 100,0 & \\
\hline
\end{tabular}

\begin{tabular}{|c|c|c|c|c|c|}
\hline \multicolumn{6}{|c|}{ Alojamiento } \\
\hline & & Frecuencia & Porcentaje & $\begin{array}{l}\text { Porcentaje } \\
\text { válido }\end{array}$ & $\begin{array}{l}\text { Porcentaje } \\
\text { acumulado }\end{array}$ \\
\hline \multirow{3}{*}{ Válido } & SI & 107 & 32,6 & 32,6 & 32,6 \\
\hline & NO & 221 & 67,4 & 67,4 & 100,0 \\
\hline & Total & 328 & 100,0 & 100,0 & \\
\hline
\end{tabular}

\begin{tabular}{ccc|c|c|c} 
& & \multicolumn{5}{c}{ Gastronomía } \\
& & Frecuencia & Porcentaje & $\begin{array}{c}\text { Porcentaje } \\
\text { válido }\end{array}$ & $\begin{array}{c}\text { Porcentaje } \\
\text { acumulado }\end{array}$ \\
\hline \multirow{3}{*}{ Válido } & SI & 42 & 12,8 & 12,8 & 12,8 \\
\cline { 2 - 6 } & NO & 286 & 87,2 & 87,2 & 100,0 \\
\cline { 2 - 6 } & Total & 328 & 100,0 & 100,0 &
\end{tabular}

Excursiones locales, rutas

\begin{tabular}{ccc|c|c|c} 
& & Frecuencia & Porcentaje & $\begin{array}{c}\text { Porcentaje } \\
\text { válido }\end{array}$ & $\begin{array}{c}\text { Porcentaje } \\
\text { acumulado }\end{array}$ \\
\hline \multirow{3}{*}{ Válido } & SI & 75 & 22,9 & 22,9 & 22,9 \\
\cline { 2 - 7 } & NO & 253 & 77,1 & 77,1 & 100,0 \\
\cline { 2 - 7 } & Total & 328 & 100,0 & 100,0 & \\
\end{tabular}

\begin{tabular}{ccc|c|c|c} 
& \multicolumn{7}{c}{ Agencias de viajes } \\
& & Frecuencia & Porcentaje & $\begin{array}{c}\text { Porcentaje } \\
\text { válido }\end{array}$ & $\begin{array}{c}\text { Porcentaje } \\
\text { acumulado }\end{array}$ \\
\hline \multirow{2}{*}{ Válido } & SI & 154 & 47,0 & 47,0 & 47,0 \\
\cline { 2 - 6 } & NO & 174 & 53,0 & 53,0 & 100,0 \\
\cline { 2 - 6 } & Total & 328 & 100,0 & 100,0 & \\
& & & &
\end{tabular}

Amenidades turísticas

\begin{tabular}{ccc|c|c|c} 
& & Frecuencia & Porcentaje & $\begin{array}{c}\text { Porcentaje } \\
\text { válido }\end{array}$ & $\begin{array}{c}\text { Porcentaje } \\
\text { acumulado }\end{array}$ \\
\hline \multirow{3}{*}{ Válido } & SI & 119 & 36,3 & 36,3 & 36,3 \\
\cline { 2 - 6 } & NO & 209 & 63,7 & 63,7 & 100,0 \\
\cline { 2 - 6 } & Total & 328 & 100,0 & 100,0 & \\
\hline
\end{tabular}


En este apartado la mayoría valora a los servicios como regular, seguido del bueno, quedando en último lugar el malo, es decir los servicios catalogados como regulares son hospedaje $47.9 \%$, señalización $56.1 \%$, museos $47.6 \%$, información turística $54.6 \%$ y transporte $53.7 \%$ que sin lugar a duda tienen problemas por ser muy requeridos por el turista, pero con muchas limitaciones en el cantón (Tabla 7). Ahora en cuanto a los buenos esta la alimentación, la oferta cultural, el comercio, en sí los servicios deben mejorar ya que estos son los generadores de confianza.

Tabla 7. Valoración de los servicios e infraestructura de Píllaro.

\begin{tabular}{|c|c|c|c|c|c|}
\hline \multicolumn{6}{|c|}{ Hospedaje } \\
\hline & & Frecuencia & Porcentaje & $\begin{array}{c}\text { Porcentaje } \\
\text { válido }\end{array}$ & $\begin{array}{l}\text { Porcentaje } \\
\text { acumulado }\end{array}$ \\
\hline \multirow{4}{*}{ Válido } & Bueno & 156 & 47,6 & 47,6 & 47,6 \\
\hline & Regular & 157 & 47,9 & 47,9 & 95,4 \\
\hline & Malo & 15 & 4,6 & 4,6 & 100,0 \\
\hline & Total & 328 & 100,0 & 100,0 & \\
\hline
\end{tabular}

\begin{tabular}{|c|c|c|c|c|c|}
\hline \multicolumn{6}{|c|}{ Alimentación } \\
\hline & & Frecuencia & Porcentaje & $\begin{array}{c}\text { Porcentaje } \\
\text { válido }\end{array}$ & $\begin{array}{l}\text { Porcentaje } \\
\text { acumulado }\end{array}$ \\
\hline \multirow{4}{*}{ Válido } & Bueno & 216 & 65,9 & 65,9 & 65,9 \\
\hline & Regular & 99 & 30,2 & 30,2 & 96,0 \\
\hline & Malo & 13 & 4,0 & 4,0 & 100,0 \\
\hline & Total & 328 & 100,0 & 100,0 & \\
\hline
\end{tabular}

\begin{tabular}{ccc|c|c|c}
\multicolumn{8}{c}{ Señalización } \\
\hline \multirow{2}{*}{ Válido } & Frecuencia & Porcentaje & $\begin{array}{c}\text { Porcentaje } \\
\text { válido }\end{array}$ & $\begin{array}{c}\text { Porcentaje } \\
\text { acumulado }\end{array}$ \\
\cline { 2 - 6 } & Bueno & 108 & 32,9 & 32,9 & 32,9 \\
\cline { 2 - 6 } & Regular & 184 & 56,1 & 56,1 & 89,0 \\
\cline { 2 - 6 } & Malo & 36 & 11,0 & 11,0 & 100,0 \\
\hline & Total & 328 & 100,0 & 100,0 & \\
\end{tabular}

Museos centros de interpretación

\begin{tabular}{|c|c|c|c|c|c|}
\hline & & Frecuencia & Porcentaje & $\begin{array}{c}\text { Porcentaje } \\
\text { válido }\end{array}$ & $\begin{array}{l}\text { Porcentaje } \\
\text { acumulado }\end{array}$ \\
\hline \multirow{4}{*}{ Válido } & Bueno & 138 & 42,1 & 42,1 & 42,1 \\
\hline & Regular & 156 & 47,6 & 47,6 & 89,6 \\
\hline & Malo & 34 & 10,4 & 10,4 & 100,0 \\
\hline & Total & 328 & 100,0 & 100,0 & \\
\hline
\end{tabular}




\begin{tabular}{|c|c|c|c|c|c|}
\hline \multicolumn{6}{|c|}{ Oferta cultural } \\
\hline & & Frecuencia & Porcentaje & $\begin{array}{c}\text { Porcentaje } \\
\text { válido }\end{array}$ & $\begin{array}{l}\text { Porcentaje } \\
\text { acumulado }\end{array}$ \\
\hline \multirow{4}{*}{ Válido } & Bueno & 191 & 58,2 & 58,2 & 58,2 \\
\hline & Regular & 112 & 34,1 & 34,1 & 92,4 \\
\hline & Malo & 25 & 7,6 & 7,6 & 100,0 \\
\hline & Total & 328 & 100,0 & 100,0 & \\
\hline
\end{tabular}

Información turística

\begin{tabular}{|c|c|c|c|c|c|}
\hline & & Frecuencia & Porcentaje & $\begin{array}{c}\text { Porcentaje } \\
\text { válido }\end{array}$ & $\begin{array}{l}\text { Porcentaje } \\
\text { acumulado }\end{array}$ \\
\hline \multirow{4}{*}{ Válido } & Bueno & 116 & 35,4 & 35,4 & 35,4 \\
\hline & Regular & 179 & 54,6 & 54,6 & 89,9 \\
\hline & Malo & 33 & 10,1 & 10,1 & 100,0 \\
\hline & Total & 328 & 100,0 & 100,0 & \\
\hline
\end{tabular}

\begin{tabular}{|c|c|c|c|c|c|}
\hline \multicolumn{6}{|c|}{ Comercio } \\
\hline & & Frecuencia & Porcentaje & $\begin{array}{c}\text { Porcentaje } \\
\text { válido }\end{array}$ & $\begin{array}{l}\text { Porcentaje } \\
\text { acumulado }\end{array}$ \\
\hline \multirow{4}{*}{ Válido } & Bueno & 159 & 48,5 & 48,5 & 48,5 \\
\hline & Regular & 155 & 47,3 & 47,3 & 95,7 \\
\hline & Malo & 14 & 4,3 & 4,3 & 100,0 \\
\hline & Total & 328 & 100,0 & 100,0 & \\
\hline
\end{tabular}

Transporte

\begin{tabular}{|c|c|c|c|c|c|}
\hline & & Frecuencia & Porcentaje & $\begin{array}{c}\text { Porcentaje } \\
\text { válido }\end{array}$ & $\begin{array}{l}\text { Porcentaje } \\
\text { acumulado }\end{array}$ \\
\hline \multirow{4}{*}{ Válido } & Bueno & 128 & 39,0 & 39,0 & 39,0 \\
\hline & Regular & 176 & 53,7 & 53,7 & 92,7 \\
\hline & Malo & 24 & 7,3 & 7,3 & 100,0 \\
\hline & Total & 328 & 100,0 & 100,0 & \\
\hline
\end{tabular}

En la Tabla 8 se muestra que los turistas valoraron positivamente la calidad del paisaje $(73,8 \%)$, los recursos turísticos culturales $(50,3 \%)$ y el trato recibido $(61,6 \%)$, es decir muchos se sienten cómo- dos con lo que han vivido, pero consideran que es regular la limpieza de la ciudad, un problema que desmejora el sitio ya que los desechos sólidos y líquidos no son manejados adecuadamente. 
Tabla 8. Valoración de la visita turística

\begin{tabular}{|c|c|c|c|c|c|}
\hline \multicolumn{6}{|c|}{ Calidad del paisaje } \\
\hline & & Frecuencia & Porcentaje & $\begin{array}{c}\text { Porcentaje } \\
\text { válido }\end{array}$ & $\begin{array}{l}\text { Porcentaje } \\
\text { acumulado }\end{array}$ \\
\hline \multirow{4}{*}{ Válido } & Bueno & 242 & 73,8 & 73,8 & 73,8 \\
\hline & Regular & 71 & 21,6 & 21,6 & 95,4 \\
\hline & Malo & 15 & 4,6 & 4,6 & 100,0 \\
\hline & Total & 328 & 100,0 & 100,0 & \\
\hline
\end{tabular}

\begin{tabular}{|c|c|c|c|c|c|}
\hline \multicolumn{6}{|c|}{ Acceso a los recursos turísticos culturales } \\
\hline & & Frecuencia & Porcentaje & $\begin{array}{l}\text { Porcentaje } \\
\text { válido }\end{array}$ & $\begin{array}{l}\text { Porcentaje } \\
\text { acumulado }\end{array}$ \\
\hline \multirow{4}{*}{ Válido } & Bueno & 165 & 50,3 & 50,3 & 50,3 \\
\hline & Regular & 141 & 43,0 & 43,0 & 93,3 \\
\hline & Malo & 22 & 6,7 & 6,7 & 100,0 \\
\hline & Total & 328 & 100,0 & 100,0 & \\
\hline
\end{tabular}

Limpieza de la ciudad

\begin{tabular}{ccc|c|c|c} 
& Frecuencia & Porcentaje & $\begin{array}{c}\text { Porcentaje } \\
\text { válido }\end{array}$ & $\begin{array}{c}\text { Porcentaje } \\
\text { acumulado }\end{array}$ \\
\hline \multirow{2}{*}{ Válido } & Bueno & 129 & 39,3 & 39,3 & 39,3 \\
\cline { 2 - 6 } & Regular & 172 & 52,4 & 52,4 & 91,8 \\
\cline { 2 - 6 } & Malo & 27 & 8,2 & 8,2 & 100,0 \\
\hline & Total & 328 & 100,0 & 100,0 & \\
\end{tabular}

\begin{tabular}{ccc|c|c|c} 
& \multicolumn{9}{c}{ Trato recibido } \\
& & Frecuencia & Porcentaje & $\begin{array}{c}\text { Porcentaje } \\
\text { válido }\end{array}$ & $\begin{array}{c}\text { Porcentaje } \\
\text { acumulado }\end{array}$ \\
\hline \multirow{2}{*}{ Válido } & Bueno & 202 & 61,6 & 61,6 & 61,6 \\
\cline { 2 - 6 } & Regular & 109 & 33,2 & 33,2 & 94,8 \\
\cline { 2 - 6 } & Malo & 17 & 5,2 & 5,2 & 100,0 \\
\cline { 2 - 6 } & Total & 328 & 100,0 & 100,0 & \\
\hline
\end{tabular}

La Tabla 9 indica los resultados de una pregunta abierta que permitió identificar deficiencias que, en criterio de los turistas, son los más relevantes, quedando claro que los servicios turísticos en general no son buenos con el $31.1 \%$, seguido del mal manejo de las prácticas ambientales $(23.5 \%)$ e inseguridad (13.1\%). Aunque con menor porcenta- je, pero sin dejar de ser importantes, está el transporte, la desorganización de ventas ambulantes, la falta de promoción y publicidad, la inexistencia de zonas wifi, la falta de capacitación, a lo que se suman los problemas vandálicos que han atentado contra los monumentos y paredes de la ciudad como los grafitis. 
Tabla 9. Aspectos negativos de la visita turística

Encontró alguna deficiencia en su visita al cantón Píllaro

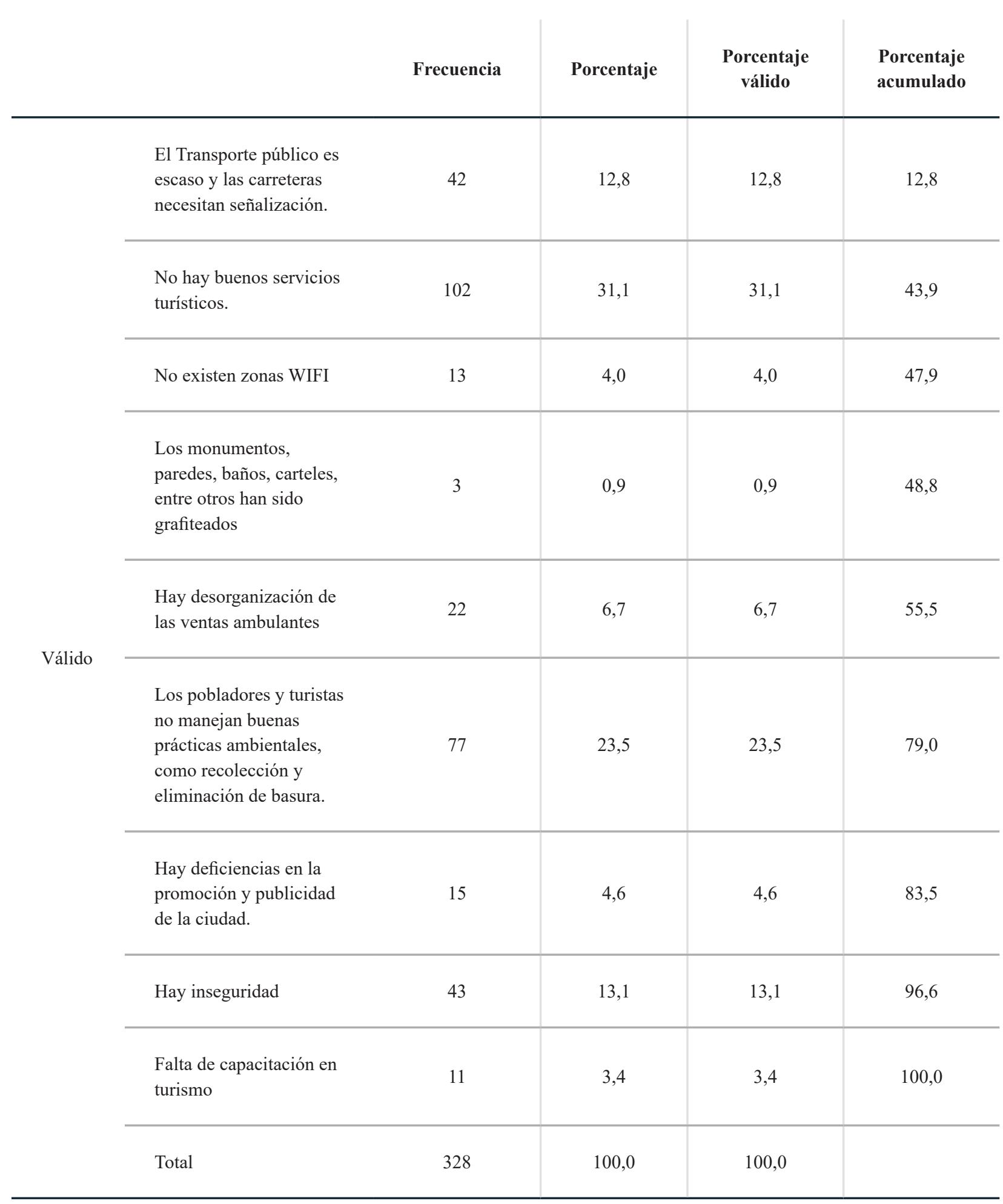

De igual manera, en la Tabla 10, un grupo significativo cree que los recursos culturales deberían fortalecerse por medio de la publicidad $(37,5 \%)$, las facilidades turísticas $(16,5 \%)$, fortaleciendo el entorno cultural (13.7\%). También, consideran necesario promover el emprendimiento turístico, motivar la creación de proyectos, y fortalecer la seguridad, redes sociales, limpieza. Las dos preguntas abiertas tienen varios puntos que coinciden y que permiten tener una idea de cómo encaminar las estrategias que dinamicen el sector. 
Tabla 10. Propuestas para fortalecer los recursos culturales de la ciudad de Píllaro.

Cómo fortalecería los recursos culturales de la ciudad de Píllaro

\begin{tabular}{|c|c|c|c|c|c|}
\hline & & Frecuencia & Porcentaje & $\begin{array}{l}\text { Porcentaje } \\
\text { válido }\end{array}$ & $\begin{array}{l}\text { Porcentaje } \\
\text { acumulado }\end{array}$ \\
\hline \multirow{10}{*}{ Válido } & $\begin{array}{l}\text { Publicitando el cantón } \\
\text { a nivel nacional como } \\
\text { internacional }\end{array}$ & 123 & 37,5 & 37,5 & 37,5 \\
\hline & $\begin{array}{l}\text { Motivando la creación de } \\
\text { proyectos turísticos }\end{array}$ & 26 & 7,9 & 7,9 & 45,4 \\
\hline & $\begin{array}{l}\text { Mejorando las facilidades } \\
\text { turísticas }\end{array}$ & 54 & 16,5 & 16,5 & 61,9 \\
\hline & $\begin{array}{l}\text { Concienciando a los } \\
\text { pobladores y visitantes } \\
\text { sobre el aseo }\end{array}$ & 8 & 2,4 & 2,4 & 64,3 \\
\hline & $\begin{array}{l}\text { Fortaleciendo el entorno } \\
\text { cultural }\end{array}$ & 45 & 13,7 & 13,7 & 78,0 \\
\hline & $\begin{array}{l}\text { Sugiriendo al GAD } \\
\text { cantonal que promueva } \\
\text { emprendimientos turístico } \\
\text { culturales. }\end{array}$ & 29 & 8,8 & 8,8 & 86,9 \\
\hline & $\begin{array}{l}\text { Capacitando a los } \\
\text { pobladores e involucrados } \\
\text { en la actividad turística. }\end{array}$ & 11 & 3,4 & 3,4 & 90,2 \\
\hline & $\begin{array}{l}\text { Optimizando el acceso al } \\
\text { internet. }\end{array}$ & 13 & 4,0 & 4,0 & 94,2 \\
\hline & $\begin{array}{l}\text { Fortaleciendo la seguridad } \\
\text { pública y privada }\end{array}$ & 19 & 5,8 & 5,8 & 100,0 \\
\hline & Total & 328 & 100,0 & 100,0 & \\
\hline
\end{tabular}

\subsection{Estrategias de dinamización turístico cultural}

En el camino para plantear estrategias de dinamización turístico cultural se analizó los resultados obtenidos en la encuesta llegando a determinar que hay interés del turista por conocer el patrimonio del cantón, el cual no ha sido puesto en valor adecuadamente, a lo que se suma la ne- cesidad de mejorar las facilidades en procura de ofrecer un servicio adecuado.

Las estrategias que se han diseñado buscan dar respuesta a los retos a los que ha de enfrentarse el cantón Santiago de Píllaro, con el único fin de ser más competitivo y posicionar el cantón como destino en el contexto nacional e internacional. 


\section{Líneas estratégicas}

Las estrategias nacen a partir de diez líneas estratégicas (Figura 1) que abarcan los principales ám- bitos de actuación, que fueron identificadas a partir del diagnóstico realizado. A partir de estas líneas estratégicas se desarrollan 27 estrategias recogidas en la Tabla 11.

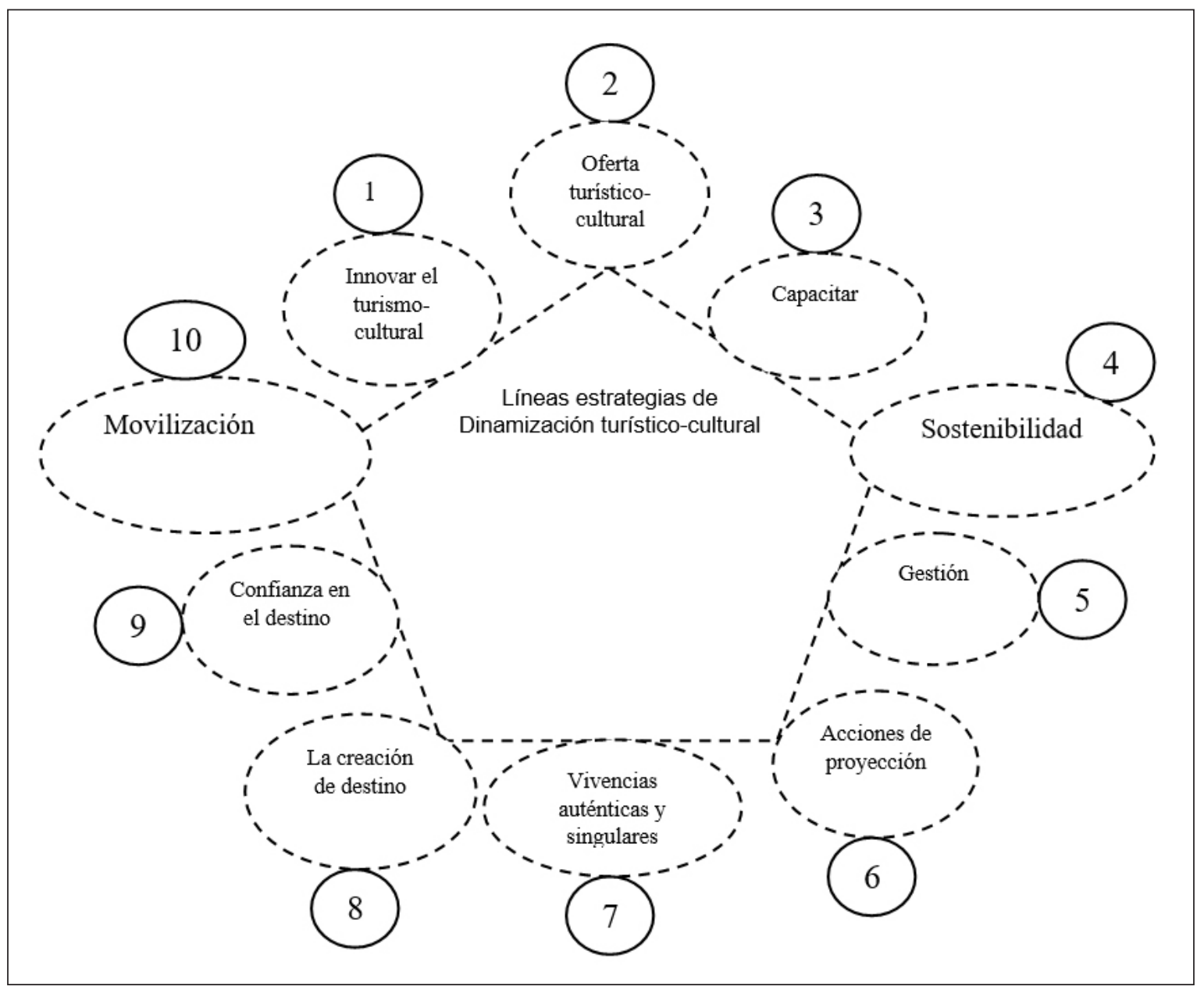

Figura 1. Líneas estratégicas de dinamización turístico cultural

Tabla 11. Propuestas para fortalecer los recursos culturales de la ciudad de Píllaro

\section{Estrategias propuestas}

1.- 10 años declarada la diablada pillareña como Patrimonio Cultural Inmaterial.

2.- Guía del viajero

3.- Itinerarios culturales

4.- Plan de recuperación del patrimonio

\section{Objetivo}

Reorientar la fiesta de la diablada pillareña con el fin de maximizar su impacto sobre el destino e instrumentarlo en pro del posicionamiento del cantón Santiago de Píllaro, aprovechando que el evento cumple 10 años el 29 de diciembre de 2018.

Mejorar el disfrute de los atractivos culturales del cantón Santiago de Píllaro por parte del visitante facilitando los soportes que precisa para conocer, comprender, recorrer y consumir durante su estancia.

Enriquecer la propuesta turística del cantón Píllaro con productos dirigidos al público que busca experiencias culturales, poniendo en valor los atractivos tangibles e intangibles de todo el cantón.

El objetivo es doble: Conservar el patrimonio mueble, inmueble y espiritual que forma parte del patrimonio del cantón. En segundo lugar, hacer este patrimonio accesible al visitante, aprovechándolo para la atracción de viajeros. 


\begin{tabular}{ll}
\hline $\begin{array}{l}\text { 5.- Actividades nocturnas en el } \\
\text { cantón Santiago de Píllaro. }\end{array}$ & $\begin{array}{l}\text { Incentivar la pernocta y el consumo en destino con una agenda de actividades nocturnas } \\
\text { dirigidas al visitante. }\end{array}$ \\
\hline $\begin{array}{l}\text { 6.- Vialidad y movilidad } \\
\text { sostenible. }\end{array}$ & $\begin{array}{l}\text { Crear un espacio urbano controlado y planificado para el turista, facilitando la movilidad } \\
\text { peatonal, y el transporte. }\end{array}$ \\
\hline & $\begin{array}{l}\text { Ofrecer al viajero la información que precisa para disfrutar al máximo de su experiencia } \\
\text { en el cantón Santiago de Píllaro, en especial la información relativa a la localización de los } \\
\text { atractivos del destino, la compra de servicios, la organización de itinerarios, la orientación en } \\
\text { el espacio, disfrute y comprensión. }\end{array}$ \\
7.- Información turística &
\end{tabular}

$\begin{array}{ll}\begin{array}{l}\text { 8.- Agenda de eventos: apoyo, } \\ \text { captación y organización de } \\ \text { eventos }\end{array} & \begin{array}{l}\text { Incentivar la visita al cantón en fechas con poca afluencia turística con una programación } \\ \text { diferente para el turista. }\end{array}\end{array}$

\begin{tabular}{l} 
9.- La gastronomía como \\
producto cultural \\
\hline 10.-Coordinación \\
interinstitucional
\end{tabular}

Contribuir por medio de la gastronomía al mercado turístico cultural del cantón Santiago de Píllaro como un destino gastronómico, tradicional para captar el turismo.

\begin{tabular}{ll}
\hline 11.- Anfitriones locales & $\begin{array}{l}\text { Hospedar a turistas que visitan el cantón por medio de la utilización de casas de pobladores } \\
\text { anfitirones para mejorar la pernoctación en el lugar. }\end{array}$ \\
\hline $\begin{array}{l}\text { 12.- Desarrollo del producto } \\
\text { turístico complejos. }\end{array}$ & $\begin{array}{l}\text { Posicionar al cantón Santiago de Píllaro como destino familiar con una propuesta en base a } \\
\text { balnearios y actividades para la familia. }\end{array}$ \\
\hline 13.- Mirador Huaynacuri & $\begin{array}{l}\text { Convertir al mirador Huaynacuri en un lugar de excepcional belleza como aporte a la captación } \\
\text { de turistas para su desarrollo turístico }\end{array}$ \\
\hline
\end{tabular}

14.- Centro de planificación turística del cantón y mecanismos de representación

(1)

15.- Imagen urbana

16.- Agenda 21

17.- Seguridad turística

18.- Plan de capacitación

19.- Digitalización del cantón

Constituir un Centro de planificación turística de acuerdo con los lineamientos establecidos en el GAD cantonal.

Planificar actuaciones que permitan homogeneizar y mejorar la imagen del cantón Santiago de Píllaro, minimizando los principales impactos negativos, para alcanzar el posicionamiento deseado como una ciudad cultural.

Acoger las recomendaciones de la Agenda 21 que se puedan implementar y desarrollar en el cantón Santiago de Píllaro como estrategia de sostenibilidad económica, social, cultural y ambiental.

Contribuir en el mejoramiento de las condiciones de seguridad tanto para los turistas como para los espacios y eventos de mayor afluencia turística.

Capacitar a los prestadores turísticos del cantón como aporte al mejoramiento del servicio y trato al turista para lograr una imagen diferenciadora.

Diseñar herramientas digitales como aporte a la difusión y promoción turística del cantón para obtener una posición en el sector turístico del país.

20.- Observatorio turístico Recopilar la información necesaria del turista y el comportamiento en el que se encuentra inmerso el sector turístico del cantón para planificar su desarrollo turístico de forma adecuada la realidad.

21.- Colaboración Universitaria

Involucrar a los centros de educación superior como apoyo al desarrollo del sector turístico del cantón Santiago de Píllaro en el proceso de innovación.

22.- Comunicación del Plan de dinamización turística

Difundir las estrategias de dinamización turístico-cultural del cantón Santiago de Píllaro y las acciones que forman parte de este como mecanismo de control sobre lo que se está haciendo para el desarrollo del turismo.

23.- Gestión turística Proponer un modelo de gestión turística como parte del desarrollo turístico-cultural del cantón para desarrollar ámbitos de actuación.

24. - Pilar turístico-cultura Implicar a los principales líderes sociales, empresariales y culturales del cantón en su promoción como destino turístico y en la atracción de eventos e inversiones. 


\begin{tabular}{ll}
\hline 25. - Cultura turística & $\begin{array}{l}\text { Implicar a los pobladores del cantón como anfitriones de los turistas para promocionar y } \\
\text { comunicar las bondades del sector. }\end{array}$ \\
\hline $\begin{array}{l}\text { 26.- Redescubriendo al cantón } \\
\text { Santiago de Píllaro }\end{array}$ & $\begin{array}{l}\text { Despertar el sentido de pertenencia hacia el cantón Santiago de Píllaro por medio de reseñas } \\
\text { historias, anécdotas, leyendas entre otros, que contribuyan al fortalecimiento del orgullo del } \\
\text { ciudadano pillareño. }\end{array}$ \\
\hline 27.- Bus turístico & $\begin{array}{l}\text { Recorrer el cantón Santiago de Píllaro, utilizando un bus turístico para quiene desen hacer una } \\
\text { vista panorámica de la bella ciudad. }\end{array}$ \\
\hline
\end{tabular}

\section{Discusión}

El desconocimiento y los pocos esfuerzos de entidades públicas y privadas por desarrollar el turismo cultural del cantón Santiago de Píllaro, constituye una oportunidad para plantear estrategias de dinamización turístico-cultural ya que en los resultados obtenidos a través de la encuesta muchos turistas no lograron identificar con certeza el trabajo en este aspecto, evidenciando claramente que no hay un programa de estrategias o si las hay no han sido visibilizadas como parte del progreso turístico del sector.

Situación parecida la han vivido otras ciudades del mundo de acuerdo a la información obtenida como es el caso de Atlixco, Almería, por nombrar algunas, siendo estos ejemplos los referentes que han permitido plantear estrategias para contribuir en el aprovechamiento de los recursos turístico-culturales, así como también corregir, mejorar y si es el caso aumentar las facilidades turísticas al igual que los accesos al lugar.

En suma, se considera que las estrategias son una alternativa válida por sus buenos resultados por lo que es necesario hacer uso de ellas enfocándolas hacia la competitividad, el desarrollo y crecimiento del lugar.

\section{Conclusiones}

Las estrategias de dinamización se han convertido en un factor importante de mejoramiento

\section{Referencias}

Almeida, F., Coll, M., Brunet, P. J., \& Monteserín, O. (2015). Los planes de excelencia y dinamización turística (PEDT), un instrumento de cooperación a favor del desarrollo turístico. Boletín de la Asociación de Geógrafos Espanoles, (39), 201-226. y desarrollo económico y social. Este proceso que comenzó en España es hoy una alternativa para diferentes lugares del mundo. Sus buenos resultados han motivado una serie de investigaciones en busca de perfeccionar la creación de estrategias en base a las características territoriales.

En el caso del cantón Santiago de Píllaro, los recursos culturales tienen un valor tan importante que se convertirían en los imanes para captar la visita de turistas nacionales e internacionales. En este sentido lo que se busca es que la actividad turístico-cultural surja como elemento complementario a las actividades agrícolas, ganaderas, además de ayudar a mitigar la emigración, generar ingresos complementarios y diversificar la economía.

Los resultados de la encuesta llevada a cabo revelaron que los eventos y ferias son los principales motivos de visita. Los elementos que desmotivan la visita es el transporte, carreteras, servicios turísticos, entendidos estos como hospedaje y alimentación.

En esta línea, para complementar su diagnóstico territorial y poner de manifiesto las repercusiones que un plan de dinamización turístico-cultural pudiera tener, es necesario llevar a cabo un análisis particularizado de cada parroquia que comprende el cantón debido a que cada una cuenta con características propias.

Cañada, E. (2017). Asistencia técnica en Costa Rica sobre dinamización turística en territorios con identidad agroalimentaria. Disponible en: http:// www.albasud.org/noticia/es/723/asistencia-t-cnica-en-costa-rica-sobre-dinamizaci-n-tur-stica-en-territorios-con-identidad-agroalimentaria 
Cañas, L., Arnandis, R. (2014). Recurso cultural, recurso turístico, producto turístico ¿Qué creó realmente el plan piloto de dinamización del producto turístico de Xátiva (Valencia)? Papers de Turisme, 55, 65-83.

Comunidad de Madrid. (2016). Estrategias de turismo de la comunidad de Madrid. Crecimiento inteligente. Madrid: Comunidad de Madrid.

Consultur. (2002). Plan estratégico de turismo Almeria. Almería: Ayuntamiento de Almería.

GAD Munipal Píllaro. (2015). Plan de desarrollo y ordenamiento territorial del cantón Santiago de Píllaro. Píllaro, Ecuador: GADM Píllaro.

Garzan, C. (2017). València Cultural: Turismo impulsa una estrategia para dinamizar la oferta de la ciudad. Disponible en: http://valenciaplaza. com/valencia-cultural-turismo-impulsa-una-estrategia-para-dinamizar-la-oferta-de-la-ciudad

Gobierno Municipal de la Paz. (2016). Dinamización turística de la laguna de Pampalarama en la Comunidad Originaria de Chacaltaya. Chacaltaya: PAMPALARAMA GMLP.

INEC. (2010). Censo de Población de Tungurahua 2010. Quito: INEC.

Instituto de Desarrollo Turístico de México. (2014). Plan de dinamización turística de Atlixco. Atlixco, México: Instituto de desarrollo turístico de México.
Instituto Nacional de Estadística y Censos. (2010). Censo 2010. Quito, Ecuador: INEC.

Junta de Comunidades Castilla-La Mancha. (2016). Plan estratégico de turismo 2015-2019. Castilla-La Mancha. Misión, visión y objetivos estratégicos. Desarrollo de planes y líneas de actuación. Ecuador: Junta de Castilla-La Mancha. Montejaque. (2015). Montejaque.es Portal Oficial. Serrania de la Ronda. Dispoible en: http://montejaque.es

Reyes, J. (2016). Plan estratégico de desarrollo turístico para dinamizar la actividad turística del cantón La Concordia, provincia de Santo Domingo de los Tsáchilas. Tesis para la obtención del título en Ingeniería en Gestión Turística y Hotelera. Universidad Nacional de Chimborazo.

Sacatoro, L. (2013). Plan de dinamización turística en la comunidad de Malinguapamba, parroquia Isinliví, cantón Sigchos, provincia de Cotopaxi. Tesis para la obtención del título en Ingeniería en Ecoturismo. Universidad Técnica de Cotopaxi.

Valladares, C. (2016). Plan para la dinamización turística-cultural de los saberes ancestrales del patrimonio cultural inmaterial en el ámbito de artes del espectáculo para el centro histórico de Riobamba, provincia de Chimborazo. Tesis para la obtención del título en Ingeniería en Ecoturismo. Escuela Superior Politécnica de Chimborazo. 